\title{
Document Tracking Technology to Support Indonesian Local E-Governments
}

\author{
Wikan Sunindyo, Bayu Hendradjaya, G.A. Putri Saptawati, and Tricya E. Widagdo \\ Data and Software Engineering Research Group \\ School of Electrical Engineering and Informatics, Bandung Institute of Technology \\ Labtek V 2nd floor, Ganesha Street 10 Bandung 40132 Indonesia \\ \{wikan, bayu, putri, cia\} @informatika.org
}

\begin{abstract}
Currently, many information and communication technologies have been used to support electronic government systems (e-gov) to become more effective and efficient. However, in the practical level, some specific issues are still needed to be handled, for example how to manage, handle and track electronic documents in the government institutions, which also can support frequent business process modification. In this paper, we propose to integrate document tracking technology into e-government business process to improve efficiency and effectiveness of e-government application in Indonesia. We offers three integrated generic models of a document tracking system. The models has been applied at a pilot project in an administration office and a city that is enthusiastic to apply a complete e-gov system. We expect that the solution approach can be applied in other local e-governments in Indonesia. Initial results show that the document tracking prototype application can enhance the productivity, clear and simplify the business process, and support process measurement, such that it can be used to improve the quality of local e-government services.
\end{abstract}

Keywords: Document Tracking, E-Government, Business Process, Information and Communication Technology.

\section{Introduction}

To accelerate and expand economic development in Indonesia, the Indonesian government has launched many research and development programs and used many technologies including Information and communication technologies (ICT) to achieve the goal, especially in bureaucratic reformation. The Indonesian bureaucratic reformation should follow these principles, namely (1) to create effective bureaucracy that can organize people and support business sector requirements, (2) to create a strong and effective bureaucracy institution, by making clean administration, responsible legislation, and independent judicial institution, (3) to create a good governance application commitment, and (4) to create feedback channel for the future planning [3]. 
To support these bureaucratic reformation programs, a document tracking system is proposed to facilitate the government work process in different sectors and layers. Currently there are some challenges in processing documents in the governmental institutions, such as:

(1) It is not easy to track the status of some documents/requests. Currently in the location of our case study, there is no document tracking system, thus document finding and tracking is done manually.

(2) Bottlenecks in the system are undetected. The work process is not measured properly, therefore the bottlenecks cannot be spotted and the process may take longer than expected.

(3) Delayed requests cannot be resolved immediately. Unclear workflow [8], manual process and undocumented delegation cause the requests frequently postponed and cannot be resolved immediately. This is due the fact that there are unclear regulations and slow decision making process in the bureaucracy.

In this paper, we propose to integrate document tracking technology into the egovernment business process. By using document tracking systems, it is expected that the e-government implementation can be achieved more efficiently and effectively. The document tracking system supports faster delivery of the documents and easier handling of documents.

We have developed a prototype of document tracking system and use Payakumbuh city government as our pilot project of document tracking system implementation. Payakumbuh was chosen because the mayor is keen to have an E-Government implementation.

The initial results show that the prototype can help the bureaucracy in finding and tracking the documents, thus it can enhance the productivity, clear and simplify the business process, and support process measurement, such that it can be used to improve the quality of local e-government services.

The remainder of this paper is structured as follows. Section 2 presents related work. Section 3 identifies the research questions. Section 4 describes the solution approach. Finally, section 5 concludes and identifies the future work.

\section{Related Work}

This section discusses definition of information and communication technology and related works on e-government and document tracking.

\subsection{Information and Communication Technology}

Information and communication technology (ICT) is a big umbrella of terminology used for covering all technical devices to process and convey information.

ICT includes two different aspects, namely information technology and communication technology. Information technology covers all about how to process information, the utility of information as a tool, and how to manipulate and manage information, 
while communication technology involves all about how to use tools to process and transfer data from one device to others. That's why we can't separate those two concepts [4].

\subsection{ICT Development Principles}

Development and implementation of ICT in the government are based on these principles [1].

a. Human Resources Quality Improvement Principle

The development and implementation of information technology should be able to strengthen and improve human resources quality, internally and externally.

b. Synergy Principle

The development and implementation of information technology should be able to integrate all available information in the government effectively to support decision making process. The standardization of data and information between institutions is required to support this synergy principle.

\section{c. Utility Principle}

The development and implementation of information technology should become more efficient, economical, and effective. The system should be able to deliver information faster, more accurate and on time so it can be used for decision making.

\section{d. Flexibility Principle}

The development and implementation of information technology should be done in modular and incremental way to guarantee the flexibility of the systems to adapt internal and external changes.

e. Security and Reliability Principle

The reliability of information technology development and implementation should be guaranteed, such that it can be used anytime. The security and confidentiality of the data should follow the rules and regulations.

\section{f. Legality Principle}

The development and implementation of information technology should obey the law, i.e. respect the intellectual property right, including copyrights and other rights that are protected by the laws.

\section{g. Equality of Access Rights Principle}

The development and implementation of information technology should guarantee and provide the equality of access rights to governmental information which is open to the public. This principle is intended to avoid digital gaps in certain regions or society.

\section{h. Open Systems, Open Source and Legal Software Principle}

The development and implementation of information technology is using open system standard, such that it can integrate different technologies efficiently. The government is expected to use open source application to increase efficiency, economic value to investment, and avoid absolute dependency to certain companies and support IGOS (Indonesia, Go Open Source) movement. If the government uses proprietary applications, it should consider legality aspects [7]. 


\section{$2.3 \quad$ E-Government}

E-Government (electronic government, digital government, online government, or connected government) consists of the digital interactions between a government and citizens (G2C), government and businesses/Commerce (G2B), government and employees (G2E), and also between government and governments /agencies (G2G). Essentially, the e-Government delivery models can be briefly summed up as [2]

(1) G2C (Government to Citizens)

(2) G2B (Government to Businesses)

(3) G2E (Government to Employees)

(4) G2G (Government to Governments)

This digital interaction consists of governance, information and communication technology (ICT), business process re-engineering (BPR), and e-citizen at all levels of government (city, state/province, national, and international) [9].

\subsection{Document Tracking}

In products distribution and logistics, the product tracing and tracking should consider the process of tracking the location of certain item or property (including other information), for example documents.

Some researchers have been developing document tracking systems as follows.

(1) Schick and Ruland [5] proposed a new security services that provides reliable technologies for traitor tracing

(2) Solic et al [6] proposed an RFID-based location tracking system as the next generation communication services in business processes for distributed offices

\section{Research Issues}

The research issues are defined as follows.

(1) How to integrate document tracking system into the e-government business process, including the governmental organization, its environmental interaction, the workflow and rules.

(2) How to model the document tracking system and implement it.

\section{$4 \quad$ Proposed Solution}

This section presents answer to the research issues mentioned in Section 3. We design the document tracking system first and then implement the prototype of it.

\subsection{Document Tracking System Modeling}

We found that there are at least two categories of document that should be tracked in a organization. 
(1) A document approval tracking: A document that is sent by a user to an organization and this document need to get back to this user after a specific process is performed.

(2) A letter or document delivery: An incoming letter or document need to be enrouted to the right person or unit. The letter or document may be originated from internal or external sources.

A document approval tracking is needed when somebody requests an approval from a department body. A person can submit an application document for approval, and a department or unit should examine this document finally give an approval or disapproval. While waiting for the approval process, this person should be able to track his application. This model gives the benefits that the applicant can always check the progress of his/her online application. In addition to that, at the same time people from the department could be encouraged to process the application faster.

An incoming documents or letters are sorted, and sent to the person in charge to handle the documents. The incoming documents sometimes are in the form of a mail letter. The documents sometimes are routed from high level of management hierarchy to lower level. We classify the routing process into two types:

(1) A document or letter that needs a response from a destination unit back to the origin unit or other specific unit

(2) A document or letter that does not need a response.

In both cases, the origin unit usually needs to know that the letter or document is actually reached its destination. The system need to show that the document or letter is actually received. The sender of the documents or letters may come from external parties or from internal unit. The sender unit may need to be able to track down the documents.

Therefore each document should be marked with a unique identification. By using this identification, we can always trace the location of documents. A visualization of this tracking is preferred method to help trace these documents. A notification system can also be used to inform the source if needed.

A visual interaction is a benefit, and we propose that it is a must to have a visual interaction for both parties. A screen can display the units involved and also the current location of the documents.

A user who submits a document can visually track the document through his browser, or by accessing company's special application. The management of an organization can make sure that each documents or letters are being taken care of by a unit.

Fig 1. and Fig. 2 show an interaction's model between the document tracking system and its environment. The sources of documents can be from different units (unit 1 , unit 2, unit 3, and so on). This model is designed to be generic so that both types of documents uses the same model. Basically the system interacts with units and also the person who is actually part of a unit. The users of the systems are actually can be just a person for Document Approval Tracking or may also be more than one unit for Document/Letter Delivery System. 


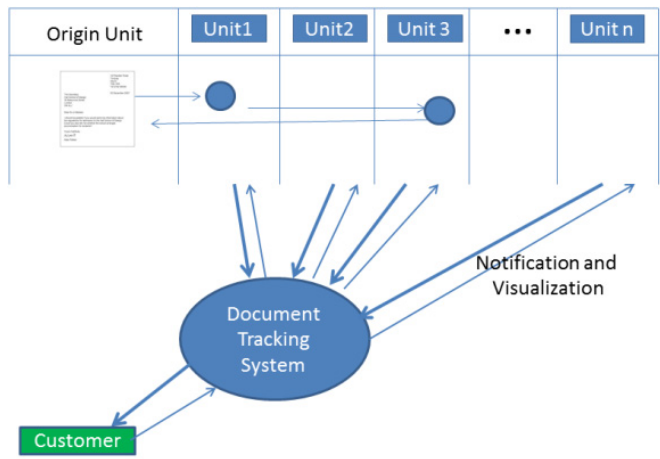

Fig. 1. Context Diagram of The Document Tracking System for Approval Tracking

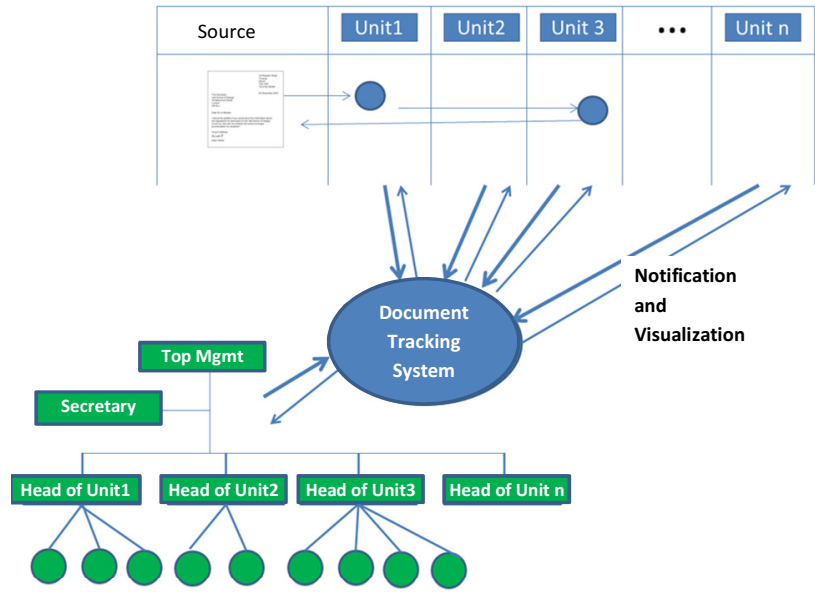

Fig. 2. Context Diagram of The Document Tracking System for Delivery of Documents or Letters

\subsection{Database Requirement Model}

The documents need to be recorded in a good database structure. The record needs two kinds of media data, namely as a binary image and as metadata of the document. As a binary image, the scan image of the actual documents (or letters) will be provided. A high speed scanner may need to be presented to scan such documents. The metadata of the document is needed for unique identification and also storing other important information (the incoming date, the sender information, and the receiver information or also the current unit). 
The model should also include information of the unit position in the organization structure. The unit position is important for enrouting a letter to the right unit. For example if a document is addressed to the organization, the document may have to be enroute the high level of management first, before it is handed into lower level unit that is responsible to handle such document (or letter).

The model should be flexible enough to be used in different kind of organizations. The model should help the application developer to define the unit structures. The unit structures can be modified by just recording the new data, without changing the structure of the database. Fig 3. shows of this database model.

The document is associated to a unit. A unit is also associated to other units. The other units can be a parent unit or the same level unit, or a children unit. A parent unit has higher hierarchical structure, and the child is a lower unit.

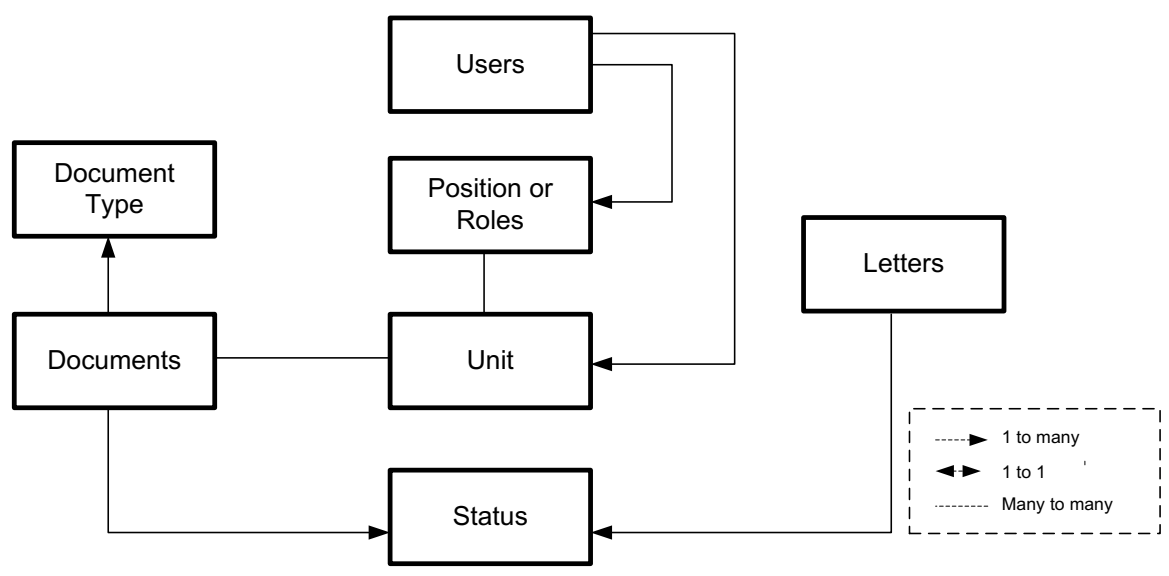

Fig. 3. Database Model

For this document tracking model, we propose a simple and generic model that is flexible to be used in different environment. However a further exploration still be needed to enhance this model.

\subsection{Implementation Model}

The system can be implemented in three platforms (Fig 4)

(1) Desktop based platform

(2) Web application (this application can be accessed by using an internet browser)

(3) Mobile application (this application can be accessed in certain platform, like Android, IOS, Blackberry or Windows-Phone) 


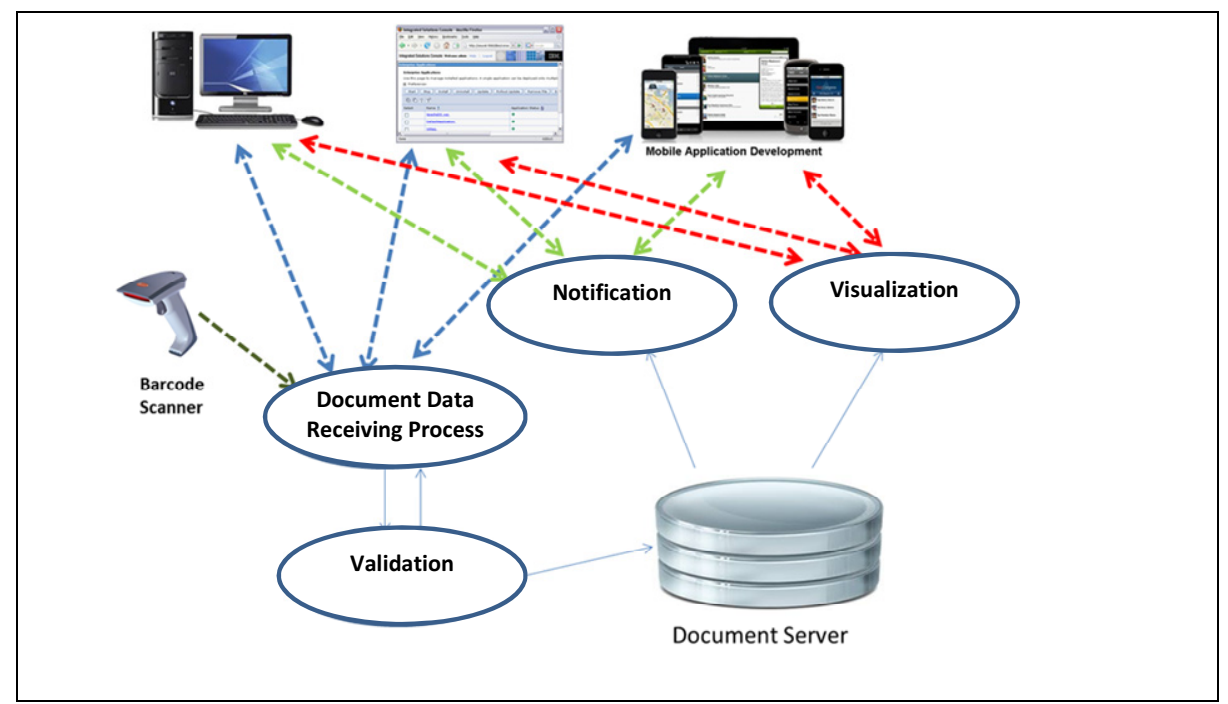

Fig. 4. Implementation Model Diagram

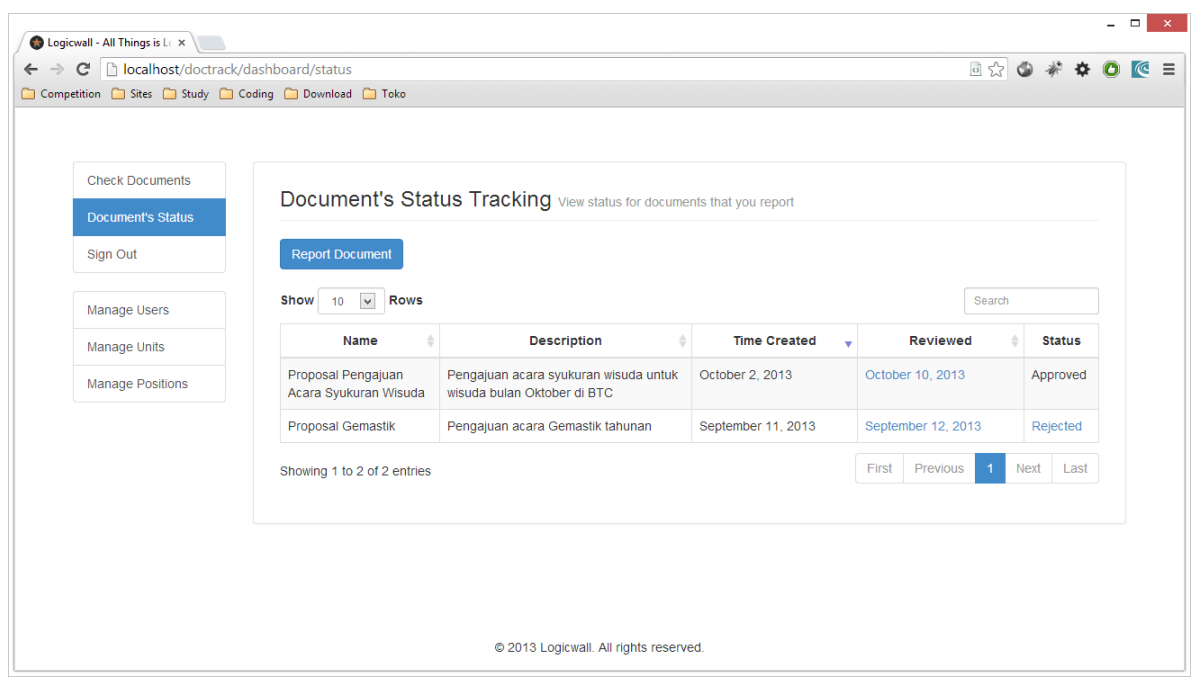

Fig. 5. Document Status Tracking Page

Currently, the prototype of the system is already implemented as a web based application and has been introduced and partially tested in Payakumbuh.

Figure 5 shows a one page example of document status tracking screen. After logging into the document tracking system, a user (e.g. a government officer) can check related documents assigned to this user. They can check and review the name, description, time created, creator, status, and notes of the documents. They can also check the detail of the document. Checking into the document's detail produces the status of the documents which can be changed during the document processing (e.g., the document has been approved or rejected). 


\section{$5 \quad$ Summary and Future Work}

Information and communication technologies are very useful to solve problems in many organizations, including in the governmental organization, such as Payakumbuh City Government. By using and integrating the document tracking technologies, makes the bureaucracy process more effective and efficient. However, current implementation model hasn't covered all possible cases of document tracking in complex institution like Payakumbuh City Government. We need to prepare for further exploration and survey after the first introduction and test of the prototype in the city government.

In this paper we have presented three models for supporting the document tracking system. The first model presents an interaction between the document tracking system and its environment. The second model offers a generic database requirement model. The last model presents how the implementation should be accomplished. An implementation of a document tracking system employs this generic model into its design.

Some non-technical issues in the implementation of the software system were found during our initial survey. The issues were related to the lack of ICT awareness from the local office people who run the department. Many of them knows how to run computer for a standard office need, however to run a customized software system needs a special skill. We recognized that running a system requires qualified users too, thus we expect that training is needed to have a successful implementation of the system.

We also need to invent new indicators to help demonstrate that the business process of an organization is actually improved after applying new tracking system. Thus another works should include defining indicators to help measuring this process. The indicators can be executed first before applying the new system to get an existing process baseline. A second execution should be performed to help evaluating the improvement from the first.

Other future works should include assessment of local governmental rules. Each local government may have slightly different rules on the handling of documents or letters. The model may have to be updated to adopt new rules; however at this stage we believe that the adoption of the model to some specific requirements should not be a difficult task.

Acknowledgements. This work has been supported by Penprinas MP3EI 2013. Thanks to Dirdik ITB and Payakumbuh City Government for supporting data and information for this paper.

\section{References}

1. BPPT: IT Master Plan Pemerintah Kota Banda Aceh 2010 - 2014 (Banda Aceh City Government IT Master Plan 2010 - 2014) (2009)

2. Hai, J.C.: Fundamental of Development Administration. Scholar Press, Selangor (2007)

3. Kementerian Koordinator Bidang Perekonomian: Masterplan Percepatan dan Perluasan Pembangunan Ekonomi Indonesia (Masterplan for Acceleration and Expansion of Indonesia Economic Development) (2011) 
4. KPDE-Kampar: Laporan Akhir Penyusunan Master Plan E-Government Kabupaten Kampar (Final Report of E-Government Master Plan Building for Kampar Regency) (2009)

5. Schick, R., Ruland, C.: Document Tracking - On the Way to a New Security Service. In: Conference on Network and Information Systems Security (SAR-SSI 2011), pp. 1-5 (2011)

6. Solic, P., et al.: ROADS: RFID Office Application for Document tracking over SIP. In: 17th International Conference on Software, Telecommunications \& Computer Networks (SoftCOM 2009), pp. 95-100 (2009)

7. Sunindyo, W.D., Akbar, S., Iqbal, M.: Towards a smart world class city - Case: Building Bandung ICT master plan. In: International Conference on ICT for Smart Society 2013 (ICISS 2013), pp. 1-5. IEEE Computer Society (2013)

8. Sunindyo, W.D., Moser, T., Winkler, D., Mordinyi, R., Biffl, S.: Workflow Validation Framework in Distributed Engineering Environments. In: Proceedings of 3rd International Workshop on Information Systems in Distributed Environment (ISDE 2011), pp. 1-10 (2011)

9. United Nations Department of Economic and Social Affairs: United Nations E-Government Survey 2012 (2012) 